\title{
The Transformation of Open Urban Space and Increasing Building Density in Hong Kong since the 1970s
}

\author{
Wei Shi, Beisi Jia and H. Koon Wee \\ University of Hong Kong, Department of Architecture, Hong Kong \\ ailswanster@gmail.com | bjiaa@hku.hk | koonwee@hku.hk
}

\begin{abstract}
The narrow concept of open space (OS) present in land-use statutes cannot cover all new kinds of open urban space (OUS), however they must take responsibility for various open spaces in real-life cities, especially in contemporary high-density built environments. Open urban spaces are inserted into buildings or their accessibility is controlled by gated systems. A systematic and comprehensive approach to studying and evaluating the way in which OUS is changing is still lacking - especially from an architectural perspective. We put forward the Level-Type (L-T) framework to analyse the OUS system in central area of the Wan Chai and Yau Tsim Mong Districts, according to an expanded concept of OUS. In this paper, we illustrate the empirical studies from the first level of our research, to demonstrate how to use the new approach to evaluate the impacts of increasing density in the pattern of OUS. This study is fundamentally a qualitative study, however some data analyses act as auxiliary references to interpret changes observed in spatial planes and models. Following a three-step comparison of the changes in spatial forms and relevant data available since 1975, we found that all types of OUS are influenced - to different extents - by increasing trends and the speed at which they occur. Four kinds of relationships between increasing density and the transformation observed in the pattern of OUS are revealed. Moreover, with exception to the fourth kind of relationship - in which the changes observed in OUS are hardly a result of increasing density or the rate at which it occurred - we extract three main characteristics of OUS transformation from the remaining three kinds of relationships, which increase in density respectively. Furthermore, these characteristics of transformation can also explain the current recognition conflicts surrounding OUS from different perspectives and scales. This study method and resultant findings could prove very useful for managing and analysing the OUS system in high-density cities.
\end{abstract}

Keywords: open urban space, Hong Kong, high-density cities, increasing density, level-type framework

To cite this article:

Shi, W., Jia, B. and Wee, H. K. (2019). The Transformation of Open Urban Space and Increasing Building Density in Hong Kong since the 1970s. The Journal of Public Space, 4(2), 9-28, DOI 10.3289I/jps.v4i2. I202

This article has been double blind peer reviewed and accepted for publication in The Journal of Public Space.

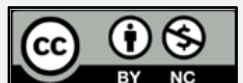

This work is licensed under a Creative Commons Attribution - Non Commercial 4.0 International License https://creativecommons.org/licenses/by-nc/4.0/ 


\section{Introduction}

During the 1970s, the inner city of Hong Kong Special Administrative Region entered a new phase of gradual reconstruction which introduced higher buildings. Following economic transformation, increasing land-prices became the most critical inducing factor for the renewal. In the process, urban spaces performed in various ways in relation to their original parts, resulting in a range of effects such as confrontation, juxtaposition, interweaving, combination, mutation, evolution, and so on. Following the diversified attributions of openness in urban spaces in Hong Kong, many studies and suggestions were explored to find opportunities for establishing high-quality urban spaces. So far, there is no comprehensive study analysis on OUS, for the most part previous studies focus on public space as being one part of open space. Previous discussions have been developed on the reasonability of urban space patterns according to the positioning of people in these spaces. There are three main positions taken by relevant previous studies; (I) considering the open urban spaces equal to public spaces that various marginal populations should be encouraged to use by providing flexible and informal utilities on a relatively small scale (Xue, 200I); (2) considering urban spaces with unlimited accessibility for the previous mainstream population, whose positions have been gradually taken over by new groups of the population (Wang \& Chen, 2018) - a process caused by the economic transformation taking place in Hong Kong. These urban spaces are mainly places of conflict, as previous vital resources are gradually being driven away from original urban spaces because of the process of renewal; (3) considering urban space with open permissions for the new mainstream population in response to the commercial performance that has almost become the main driving force behind the city's general benefits for daily life. These urban spaces exhibit the chasing of interests at all kinds of scales (Al, 2016).

The conflicts in open urban spaces (OUSs) in Hong Kong mostly arise from the displacement of the mainstream population in the inner city and is closely related to the changes in a mainly targeted population that inhabits these spaces. With this in mind, progressive planning and minimum interventions for urban structures is much more appropriate than the alternative aggressive operations. However, because the economic machine is in high-speed operation, a large amount of renewal in small spaces is inevitable (Lai, 20I5). As a result, the renewal process still seems radical and rife with conflict. Therefore, during this period, it is essential to understand the consequences of spatial replacements with the aim of exploring the possibility of coordinating private properties with public benefits. Seeking out the potential inherent in OUS should not be arbitrary, which if so could waste a lot of time and public resources. Currently, there is a great need for continued diversification of open urban space, but a framework of study which is flexible enough to mitigate a series of multiple, time-sensitive changes against the backdrop of a holistic open urban space system is still a long way off (Cuff \& Sherman, 20l I). A comprehensive and complete understanding of the specificities of any particular area is a useful and reliable way to help adjust the OUS system overall (Storper \& Scott, 2016; Wu, Wilkes, Silver \& Clark, 2019). In this study, we put forward the concept of urban open space (OUS) as the study object. OUS should include all kinds of urban space with varying degrees and modes of openness, such as: open to the air, open to the public, and publicly owned. And the L-T framework is an open framework for studying the urban spaces that are included in this study with the aim of 
filling the gap created by an absence of specific suggestions for managing open urban spaces in high-density cities, in the context of a comprehensive and dynamic urban space system. In this study, by comparing the cases in the central area of the Wan Chai District (around the Causeway Bay) and Yau Tsim Mong District (around the Mong Kok), we summarise four kinds of relationships between the pattern of OUS and increasing density. Furthermore, three characteristics of the transformation of OUS are identified, which suggest that we ought to adjust the stereotypes of negative influences arising from very high density in OUS and focus instead on identifying more opportunities during the process of increasing density. The study methods and findings are crucial references for further development of OUS.

\section{Methods}

2.I Statistics analysis

Although this study is fundamentally a qualitative study, some data analyses act as auxiliary references to interpret changes observed in spatial planes and models. Three groups of parameters are calculated to discover the relationships between patterns of OUS and increasing density. These parameters relate to: density, spatial form, and the proportion of different types of OUS. We used ArcGIS software to filter and correct historical data. And Excel was used to draw visual diagrams to directly compare trends. During the process of statistical analysis we settled upon two strategies to adopt during the study design for developing this analysis with the aim of solving problems from an architectural perspective. The first is a calculation formula for density. In this study, all visible ground floors and construction areas were included in the density calculation, along with podium floors at the ground floor level. Considering that planned roads dedicated to vehicles are usually isolated from pedestrian areas, they are not included in the construction area, and their surface area and forms have remained almost unchanged since 1975 (Shi, Jia \& Wee, 2017). Parts of the roads were also eliminated from density calculations.

As a result, building density is used as the main parameter in this study rather than the plot ratio of the whole region. The second strategy is data collection. During the process of calculation, we found there to be a lack of records concerning the outlines of towers in the 1975 and 1992 geographical maps. Some towers are mapped, while others are not. At the same time, the tower outlines cannot simply be copied from the 2014 map, because some buildings were replaced with new ones with similar podium floor outlines. The different outlines of towers can influence the density calculation to a large extent. Therefore, it was necessary to check the year in which each of the towers was constructed, one by one, in records available from real estate companies and The Land Registry of HKSAR. The outlines of these towers from historical maps were subsequently added. The parameters of OUS in three periods of history were calculated respectively to uncover the trends of transformation of OUS, as listed in the table (Table I). 
The Transformation of Open Urban Space and Increasing Building Density

\begin{tabular}{l|l|l|l}
\hline 1 & $\begin{array}{l}\text { Parameter about intensity of } \\
\text { constructions }\end{array}$ & 8 & Parameters for each Level analysis \\
\hline 2 & Building density & 9 & Population \\
\hline 3 & Density of the whole district & 10 & Density \\
\hline 4 & Construction coverage & 11 & Average nearest neighbour distance \\
\hline 5 & Average floor numbers & 12 & Coverage \\
\hline 6 & Plot ratio of towers above podiums & 13 & Average floor numbers \\
\hline 7 & Spatial volume & 14 & $\begin{array}{l}\text { Length of all OUSs' connected edge on the } \\
\text { ground }\end{array}$ \\
\hline
\end{tabular}

Table I. The parameters for studying the changes of OUS

\subsection{Mapping analysis}

This study not only examines the trends of data by making visual $2 \mathrm{~d}$ and $3 \mathrm{~d}$ maps of various OUSs in a fine scale, but in addition, the sites which best represent each type of OUS were selected for study on each of the maps respectively. The representative sites were selected one by one according to the L-T framework (Shi, Jia \& Wee, 20I6; 20I7). There are five main criteria for this selection process; (I) to choose the most obvious, large piece of each type of OUS (Figure I); (2) to choose locations close to important regional business centres planned according to the Statutory Planning process enforced by the Hong Kong Town Planning Board; (3) to select locations relatively near to pedestrian areas or streets planned by the Transport Department of the Hong Kong Government; (4) to select locations in the geographical centres of these districts; and (5) if several representative locations are found by adhering to the above disciplines for one type of OUS, to choose the relatively popular location, according to field investigations. After representative locations were selected, their planes, façades, sections and 3D models were extracted from our updated and accurate digital maps for further comparison.

Analyses on both drawings and data were conducted after selecting these representative sites. Although comprehensive study on different scales is still relatively rare, the morphological interpretation methods for reading spatial forms, describing urban spatial evolution and establishing terminologies in the context of urban structure and tissues are relatively mature. In this study, the descriptive customs and terms derived from morphological study methods, including statements about the street, plot, land-use, and building fabric, are adopted for narrating the changes observed in the pattern of OUS since 1975. In this study, the reasons behind the generation and influence of these spatial changes are also examined for each selected site, by comparing maps and historical materials from different periods. 


\begin{tabular}{|l|c|c|c|c|c|c|c|c|}
\hline & T1 & T2 & T3 & T4 & T5 & T6 & T7 & T8 \\
\hline $\begin{array}{l}\text { Outdoor } \\
\text { /Indoor }\end{array}$ & + & + & + & + & - & - & - & - \\
\hline $\begin{array}{l}\text { Public } \\
\text { own } \\
\text { /Private } \\
\text { own }\end{array}$ & + & - & + & - & + & - & + & - \\
\hline $\begin{array}{l}\text { Accessible } \\
\text { for public } \\
\text { without } \\
\text { /with } \\
\text { conditions }\end{array}$ & + & + & - & - & + & + & - & - \\
\hline
\end{tabular}

Figure I. Different types of OUS are defined by attributions

\subsection{Case comparison}

Three kinds of comparison were developed to unfold the relationships between the evolution of the pattern of OUS and increasing density; ( $I$ ) a comparison of changing plots, between 1975 and 20I4. By comparing the density, projected area and construction area of changed and unchanged plots during two periods, the comprehensive spatial evolutions in the central area of the Wan Chai (around the Causeway Bay) and Yau Tsim Mong District (around the Mong Kok) are revealed; (2) a comparison between different periods of each type of OUS. This comparison was developed by comparing several aspects of each representative site in 1975, 1992 and 2014. The comparable aspects include changes in levels, land-use, and constitutions of surrounding OUSs, driving factors for remaining OUS, social influences, and 3D models. Additional relevant data was also compared during this process, including building density and coverage, projected area and construction area, and the length of connected boundaries; (3) a comparison of two cases which involved comparing each type of OUS, one by one, to find similarities and differences between the study areas of two districts. Similar trends of changes were observed in both cases in regards to transformations seen in OUS as a result of different rates of increasing density. However, different trends of changes implied that the different rates at which density increased also played a role in the transformation of OUS. We classified four groups of different types of OUS. Moreover, discussion about the relationships between increasing density and changes in OUS patterns developed naturally.

\section{Analysis Results}

\section{I The impact of increasing density on the pattern of OUS in Wan Chai District}

\section{I.I Comprehensive spatial evolution in Wan Chai District}

Wan Chai District is located at the centre of Victoria Harbour in the north of Hong

Kong Island. The segments B02, B03, and B06 in Wan Chai District Council are taken as the study's geographical scope ("20I5 District Council Election Constituency

Boundaries", 20I5). This region is one of Hong Kong's oldest areas and is infused with a rich tapestry of traditional culture and contemporary living customs. When demolished and updated constructions are considered, the primary changes of urban form can be deduced. The plot is used as the minimum unit for mapping. Two plans are mapped and 
examined (Figure 2) (Table 2). The first, the map of changed plots in 1992 shows similar ratios between the remaining ground area and the construction area of buildings constructed in different periods at 60\%: $40 \%$. Thus, in 1992, the remaining area, which was built on or before 1975, had almost the same building density as the renewed area, which was rebuilt during 1972-1992. The second, the map of the changed plot in 2014 reveals that the proportions of remaining ground areas during the three periods were as follows: $53 \%$ (constructed before the 1970s), 30\% (constructed during 1975-1992), and $17 \%$ (constructed during 1992-2014). At the same time, the remaining constructed areas in each of the three periods were $41 \%$ (constructed before 1975), 31\% (constructed during 1975-1992), and 28\% (constructed during 1992-2014). An apparent difference between the two groups of proportions can be noted. Specifically, the renewed construction area after 1992 is more than 1.6 times the ground area $(28 \%$ to $17 \%$ ), while the proportions of the two other periods are similar (41\% to $53 \%$ and $30 \%$ to $31 \%)$. The difference shows that the buildings constructed during 1992-2014 are considerably higher than the remaining buildings, which were built before 1992. In summary, the findings were unpacked as follows; (I) During 1975-1992, the renewed building heights were similar to those of the remaining ones because the street structure had not changed since 1975. Density increase mainly relied on building construction on previously undeveloped land; (2) during 1992-2014, although the projected area of renewed plots is much smaller than that of the remaining plots, new buildings were considerably higher than previous ones. This kind of development is a welfare consequence of increasing density during 1992-2014 in the study area of the Wan Chai District.

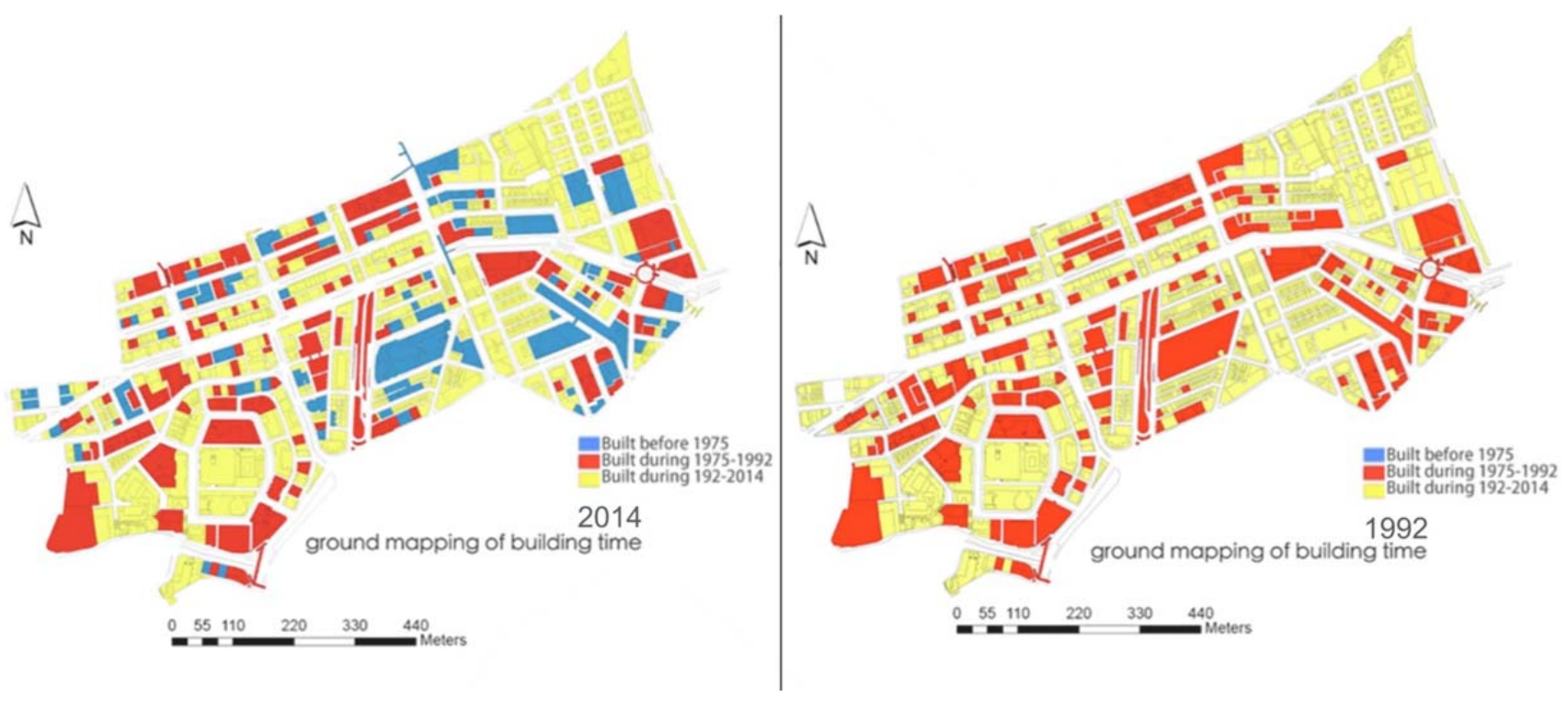

Figure 2. Changed plots in the study area of the Wan Chai District 


\begin{tabular}{l|c|c|c|c|c}
\hline $\begin{array}{l}\text { The case in } \\
\begin{array}{l}\text { Wan Chai } \\
\text { District }\end{array}\end{array}$ & \multicolumn{3}{|c|}{2014 map } & \multicolumn{2}{c}{1992 map } \\
\hline \begin{tabular}{l|c|c|c} 
Built period \\
Projected \\
area $(m)$
\end{tabular} & 196410 & 110623 & 65321 & 223707 & 146974 \\
\hline Proportion & $53 \%$ & $30 \%$ & $17 \%$ & $60 \%$ & $40 \%$ \\
\hline $\begin{array}{l}\text { Building } \\
\text { area }(m)\end{array}$ & 1752618 & 1310881 & 1172174 & 2004004 & 1309450 \\
\hline Proportion & $41 \%$ & $31 \%$ & $28 \%$ & $60 \%$ & $40 \%$ \\
\hline
\end{tabular}

Table 2. The areas and proportion of the changed plots according to the map in the case of Wan Chai District

\section{I.2 Different Types of OUS in Wan Chai District}

Mapping all types of OUS in the 1975, 1992 and 2014 maps, exhibits the constitutions of relations among different types of OUS on the ground and podium levels respectively. $A$ three step process was conducted to examine the trends in proportion evident in various OUSs since the year 1975. These were; (I) mapping different types of OUS in 1975, 1992 and 2014. Different types of OUS are scattered relatively evenly throughout the whole area. They do not form an obvious pattern of assembly in the study area of the Wan Chai District. Many new types of OUS appeared on the podium floor and replaced previous residential spaces after 1992 (Shi, Jia \& Wee, 2018); (2) Analysing the trends in proportion evident in various projected areas of OUSs. The basic area constitutions of these different types do not exhibit much change, while conversely, newly appearing types of OUS, which were considered as 'blur areas' have been witnessing a sharp increase in development since 1975. Analysing the stacked diagrams which further detail the proportions of different types of OUS: although traditional outdoor public space has been reduced, the " $Z$ " shape of the red reference lines illustrates that newly appearing types of OUS filled the small vacancy left by traditional ones, a process which has been decreasing slightly since 1975 (Figure 3). These new types of OUS have similar essential attributes to the traditional ones. And they are divided into sub-types in the L-T framework. The patterns of OUS present the diversification in the form of adjusting constitutions of relations among various types of OUS; (3) The second stacked diagram relating to projected area illustrates the reason for the changing constitution of different types of OUS (Figure 4): this change is mainly due to the fact that newly appearing types of OUS were continuously located in places outside of the previous scope of land allocated to OUS, such as upon the podium or on previously uncultivated land in urban or totally private and closed land areas. This also implies that the increasing total land area for locating OUS was also an interference factor for judging the direct increasing or decreasing of the area occupied by OUS. There were three findings that could be summarised during this process of analysis. Firstly, the total projected area of OUS has continued to increase since 1975, due to the rising quantity of newly appearing types of OUS, which lay outside of traditional land 
allocated to OUS. Secondly, the podium level is the main area of expansion for these new types of OUS. Thirdly, since 1975, various types of OUS on the ground floor exhibit a gradual trend of aggregating small pieces of the same type of OUS into large pieces. These aggregated OUSs also tend to have more irregular boundaries for the purposes of connecting with as many other types of OUS as possible. This implies that connections between different types of OUS with longer edges are preferred for new OUS built during the last four decades.
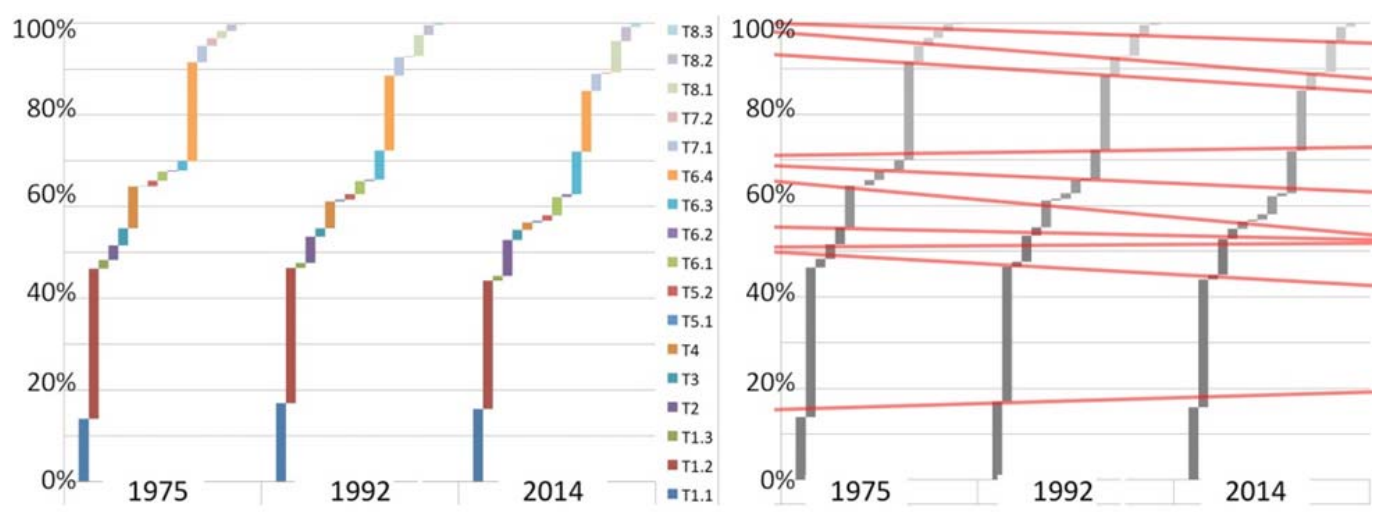

Figure 3. The proportion of different types of OUSs' projected areas in the case of the Wan Chai District
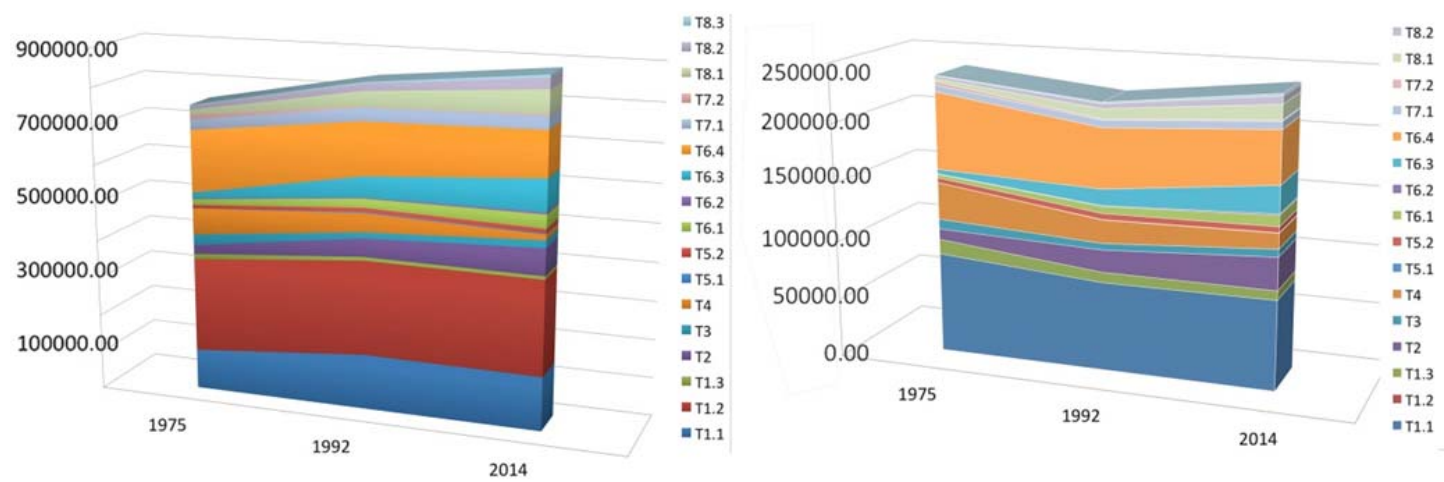

Figure 4. The stacked diagram showing different types of OUSs, their projected areas and lengths of their boundaries in study area of the Wan Chai District

\section{I.3 Changes in the pattern of OUS in the case of the Wan Chai District}

By discussing three aspects of representative sites which are changes in spatial forms (Table 3), the driving forces behind those changes, and social influences: the trends in the changing patterns of OUS in the study case of the Wan Chai District in response to increasing density can be ascertained (Table 4). When the representative OUSs of each of the different types are considered individually, there are four findings that can be summarised in regard to the changes in the pattern of OUS in the case of the District which occurred as a result of the impact of increasing density, beginning in the year 
1975. Firstly, both the quantity and quality of OUS on publicly owned land have improved since 1975. Secondly, the OUS on privately owned land relating to contemporary commercial activities has benefited from more prosperous and influential developments than OUS on publicly owned land has. Business benefit is the primary driving factor behind the increase in OUS on privately-owned land. Thirdly, various connected OUSs on the podium level improve the efficiency of the whole OUS system in the case of the Wan Chai District by improving the edges along the connections lying between different types of OUS. Fourthly, these continuously replaced or adjusted forms of different types of OUS imply that they are still not suitable enough to respond to the needs of this district. However, the commercial driving force behind the increase in OUS is only increasing in power in terms of its ability to improve OUS in the study area of the Wan Chai District. In addition, since 1975, it has largely and increasingly proven to cooperate with other driving forces.

\begin{tabular}{|c|c|c|c|c|c|c|}
\hline \multirow{3}{*}{ Type } & \multicolumn{3}{|c|}{ Planes } & \multicolumn{3}{|c|}{ Models } \\
\hline & \multicolumn{3}{|c|}{ Location -2014 map $(120 \mathrm{~m} * 200 \mathrm{~m})$} & \multicolumn{3}{|c|}{ Location -2014 map $(120 \mathrm{~m} * 200 \mathrm{~m})$} \\
\hline & $1970 s$ & $1990 \mathrm{~s}$ & $2010 s$ & $1970 s$ & $1990 \mathrm{~s}$ & $2010 s$ \\
\hline Type & & & & & & \\
\hline
\end{tabular}

Table 3. Example of a table for organising and comparing respective OUSs in the case of the Wan Chai District

\begin{tabular}{|c|c|c|c|}
\hline Year & 1975 & 1992 & 2014 \\
\hline Building density & 5.23 & 7.14 & 9.47 \\
\hline $\begin{array}{l}\text { Average distance to the nearest } \\
\text { neighbour distance }(m)\end{array}$ & 5.48 & 5.85 & 5.65 \\
\hline Coverage of blocks & 0.53 & 0.58 & 0.66 \\
\hline Average floor numbers & 7.2 & 9.2 & 10.2 \\
\hline Length of connected edges $(\mathrm{m})$ & 137986 & 117424 & $|1614|$ \\
\hline
\end{tabular}

Table 4. The parameters of OUSs in the case of the Wan Chai District 


\subsection{The impact of increasing density on the pattern of OUS in Mong Kok}

\subsection{Comprehensive spatial evolution in Mong Kok}

The segments EI3, EI5, and E06 in Yau Tsim Mong District Council are taken as the study's geographical scope ("20I5 District Council Election Constituency Boundaries," 2015). The study area is usually considered as the Mong Kok. In this article, we use the Mong Kok to present the study area in the Yau Tsim Mong District. Since the 1970s, the coverage of blocks in Mong Kok already reached a threshold (Table 4), while building density had been increasing rapidly: rising from 5.99 to 7.3. By referring to the maps of changing plots both from 1992 and 2014, one can observe that the renewal of these plots during 1975-2014 was relatively uniformly distributed throughout the whole district (Figure 5). Moreover, both large and small plots were reconstructed during 1975-2014. On the 2014 map of changed plots, the remaining plots (shown in yellow) and the renewed plots (shown in red) represent $79 \%$ and $21 \%$ respectively (Table 5 ). At the same time, the proportion of areas that have been developed in both remaining and renewed plots is the same. It follows then, that in 1992 the renewed sites had similar building densities to the remaining areas. Moreover, floor numbers of newly built buildings constructed during 1975-1992 are very likely to be of a similar number to those buildings remaining in 1992.
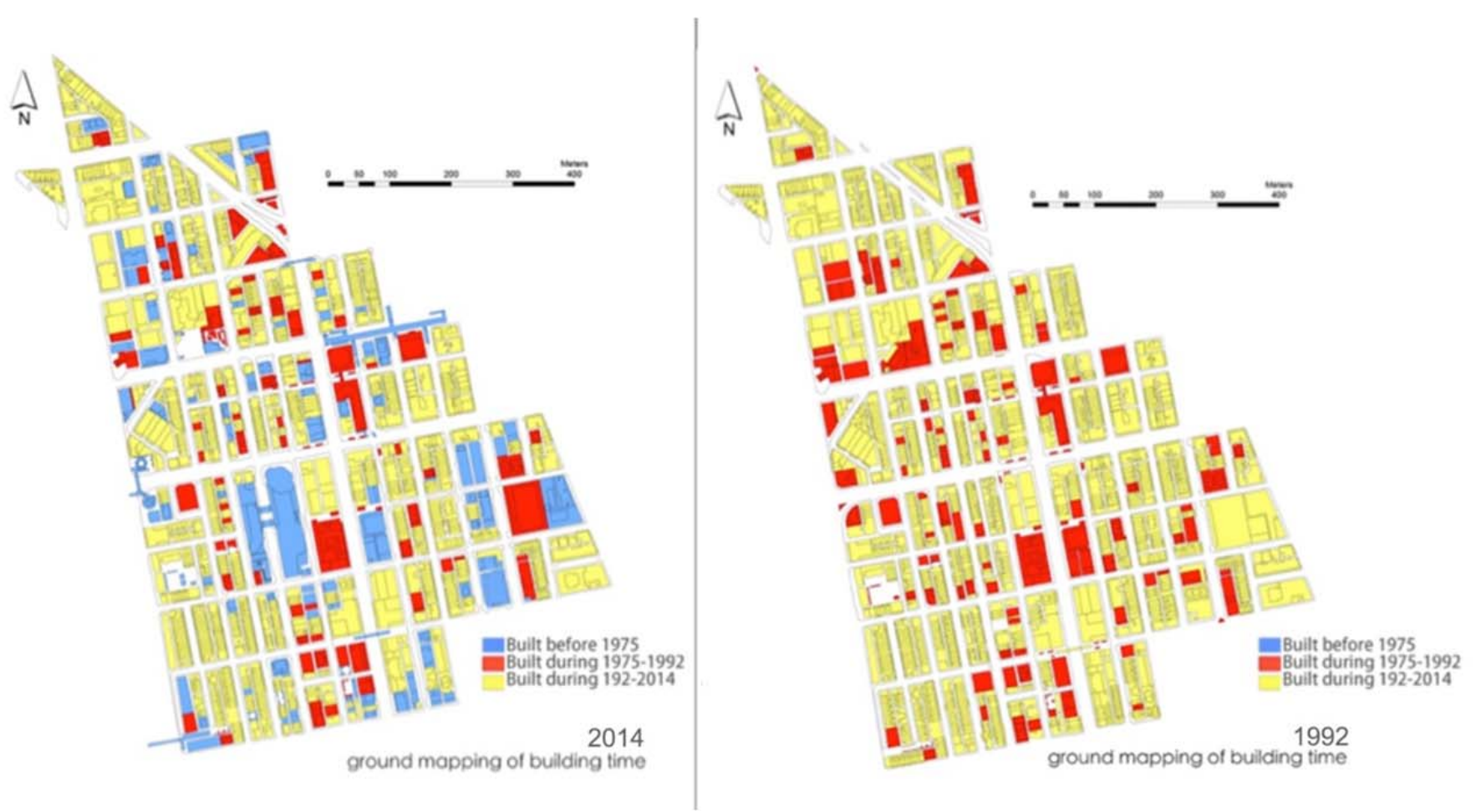

Figure 5. Changed plots in the case of Mong Kok 


\begin{tabular}{|c|c|c|c|c|c|}
\hline \multirow{2}{*}{$\begin{array}{l}\text { Mong Kok case } \\
\text { Built period }\end{array}$} & \multicolumn{3}{|c|}{2014 map } & \multicolumn{2}{|l|}{1992 map } \\
\hline & $\begin{array}{l}\text { before } \\
\text { 1975 }\end{array}$ & $1975-1992$ & $1992-20 \mid 4$ & 1975-1992 & $1992-2014$ \\
\hline $\begin{array}{l}\text { Projected } \\
\text { area }(m)^{2}\end{array}$ & 183342 & 41549 & 724792 & 225538 & 58707 \\
\hline Proportion & $19 \%$ & $5 \%$ & $76 \%$ & $79 \%$ & $21 \%$ \\
\hline Building $\operatorname{area}\left(\mathrm{m}^{2}\right)$ & 1669512 & 362439 & 1172174 & 1916534 & 522510 \\
\hline Proportion & $52 \%$ & $11 \%$ & $37 \%$ & $79 \%$ & $21 \%$ \\
\hline
\end{tabular}

Table 5. The areas and proportion of the changed plots according to the map in the case of Mong Kok

Furthermore, considering both building density and coverage show increasing trends during 1975-1992, it can be deduced that during 1975-1992, the renewed plots were mainly previously undeveloped plots and low-rise buildings. Building heights in these plots are much lower than those seen in the general remaining ones in 1992. The map of changed plots in 2014 shows the altered plots in three periods in Mong Kok: before 1975, 1975-1992, and 1992-2014. In the study area, plots changed in different periods are evenly dispersed. The blue areas, which were renewed during 1992-2014, include some obviously large pieces on the map. The proportions of projected ground area of remaining plots, which were built during three periods, as shown on the 2014 map are: $16 \%$ (before 1975), 8\% (1975-1992), and 76\% (1992-2014) respectively. And the proportions of their construction areas are 37\% (before 1975), II\% (1975-1992), and $52 \%$ (1992-2014). By comparing the two groups of proportions, it becomes clear that the remaining areas constructed before 1975 (76\%) are 9.5 times the size of the remaining areas constructed during 1975-1992 (8\%). However, the construction area of the former $(52 \%)$ is 4.7 times the latter $(11 \%)$. The difference implies that in 2014 , the building density of remaining areas that were built during 1975-1992 was approximately twice the building density of remaining plots that were built before 1975. A comparison of the two groups of proportions on the 2014 map of changed plots, revealed that the projected areas of the renewed areas built during 1992-2014 (16\%) are twice that of the remaining areas built during 1975-1992 (8\%). Moreover, the construction area of the former $(37 \%)$ is 3.4 times that of the latter (11\%). The difference implies that, in 2014 , the renewed areas that were built during 1992-2014 had a density which was about 1.7 times that of the remaining areas, which was built during 1975-1992.

\subsubsection{Different Types of OUS in Mong Kok}

The evolution of different types of OUS in the case of Mong Kok was studied according to three aspects; (I) after mapping all types of OUS on the plans of the ground and podium floors, the distribution and organisation of these different types of OUS are presented visually on the maps. 
The total projected area of the OUSs on podium floors shows an obvious increasing trend. And the projected area of the types of OUS relating to the connective parts of buildings also increases rapidly. By considering the distribution changes of different OUSs since 1975, an intangible elliptical radar shape can be realised as the path of newly appearing types which replaced previously existing types of OUS in the central area of the study area. Along the spreading ellipse, many indoor OUSs with relatively lowopenness replaced the previous residential spaces, in a gradual process since 1975. The OUS with more positive ones of the three pairs of attributions (Figure I) means it is relatively higher openness. Moreover, new kinds of OUS with mixed commercial usages and relatively high-openness replaced the 20re-existing traditional commercial spaces; (2) Comparing the proportions of different types of OUS in the case of Mong Kok in different time periods (Figure 6). The changes in the proportions of different types of OUS are not immediately obvious upon comprehensively observing their respective percentages. At first, the types of OUS with large proportions show slight decreasing trends, while the types of OUS with lower proportions show obvious increasing trends. However, both of these types of OUS keep their positions in the ranking of proportions. Although the constitution of different types of OUS in the case of Mong Kok does not change much, the acceptance of newly appearing types of OUS have been improving since 1975; (3) by studying the stack diagrams relating to the projected areas of different types of OUS - (Figure 7) the changes in vertical forms from different types of OUS can be figured out by comparing them to respective trends in relation to the lengths of their connecting edges. Although the changes in these parameters during 1975-20| 4 were relatively gentle and basically stable, some prominent contrasts did appear when we compared four other diagrams detailing the length of all the connection edges of the OUSs, these were: average floor number, coverage, and the average distance to the nearest neighbour respectively (Table 7). One of the prominent contrasts was that the total edge-length on the ground floor shows an apparent trend of decline since 1975, however, the overall length of OUS on the ground and podium floors showed a slightly decrease and then ascendant. The reasons for these different trends is that the length of the OUS on the podium floor is rising with an accelerate ratio. Furthermore, considering that the total ground area of construction land in the study area is a fixed value, when the length of the total boundaries on the ground floor decreases, the spatial form on the ground plan becomes more and more aggregated. It implies that many individual small pieces of OUS were assembled to form larger pieces during $1975-20 \mid 4$.

\subsubsection{Changes in the pattern of OUS in Mong Kok}

Three aspects relating to the pattern of selected representative OUSs are studied in this process of analysis (Table 6). They include the changes of spatial forms, driving forces behind changes, and social influences. Not only the changes in selected patterns of OUSs are analysed, but the relevant data trends from the whole study area are also compared (Table 7). 

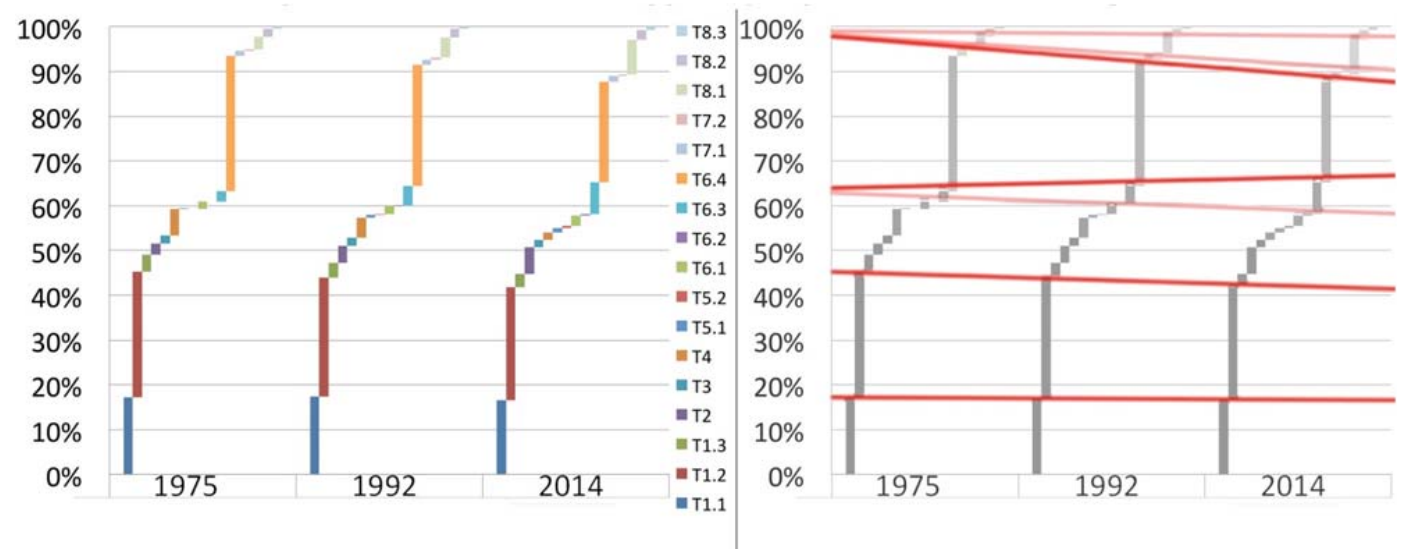

Figure 6. The proportion of projected areas in different types of OUSs in the case of Mong Kok
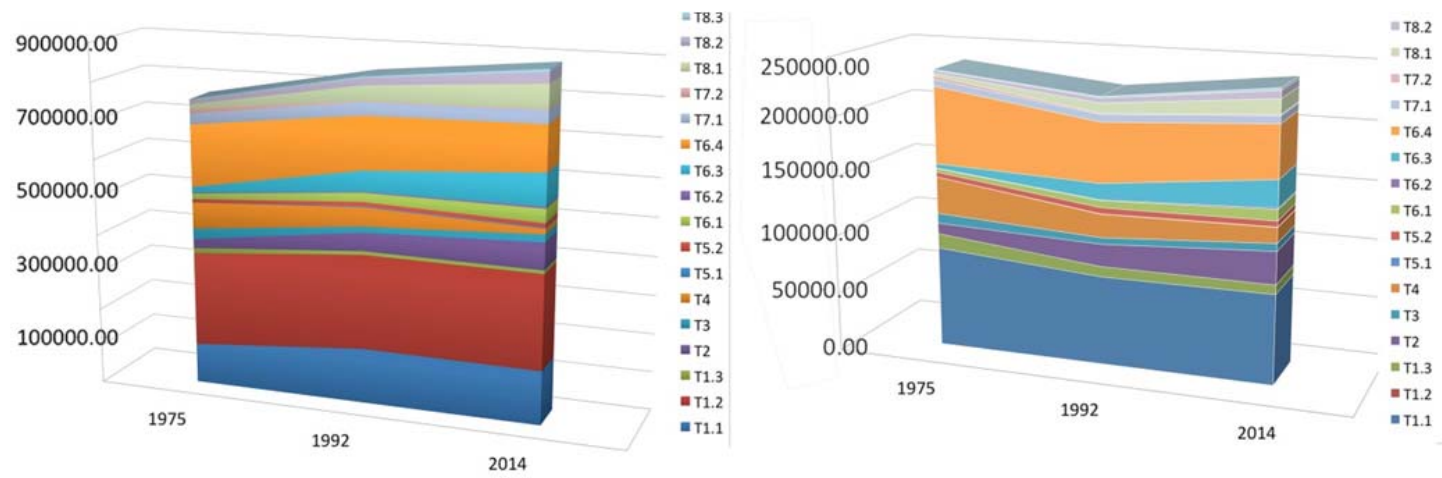

Figure 7. The stacked diagram showing different types of OUSs, their projected areas and lengthes of their boundaries in the case of Mong Kok

From this comparison we can ascertain that both the quality and quantity of these representative OUS sites have clearly been improving since 1975. The improving openness and increasing level of public-ness of newly transformed OUSs are reflected in four aspects; (I) several mega-scale structures or architectures intervene in the finely traditional urban texture. They not only bring new types and forms of OUSs but also new constitutions of spaces and relationships with public activities in to the existing built environment. These new types and forms of OUS contribute to an exciting contrast and juxtaposition of relationships between new and old groups of the population; (2) adjustments in land-use led to the production of new types of leading OUSs in this district. The appearance of new leading OUSs caused a chain reaction in the constitutions of different types of OUS around them. As a result, the efficiency of land resources and the diversity of OUSs had the chance to be balanced. (3) Different types of OUSs tend to appear on various floors, including the ground floor and auxiliary layouts, such as podium and underground floors. The vertically stacked OUS system is a common way to gain additional space for activities on both land for commercial use and publicly-owned land in Mong Kok; (4) efforts to separate vehicles and pedestrians help to improve the safety and efficiency of this district. Although the traditional types and 
forms of OUS have changed substantially, the connections between different parts are abrupt. At the same time, various groups of people tend to show apparent preferences to exclusively engage in activities in their familiar spaces.

\begin{tabular}{|c|c|c|c|c|c|c|}
\hline \multirow{3}{*}{ Type } & \multicolumn{3}{|l|}{ Planes } & \multicolumn{3}{|c|}{ Models } \\
\hline & \multicolumn{3}{|c|}{ Location -2014 map $(120 m * 200 m)$} & \multicolumn{3}{|c|}{ Location -20I4 map $(120 \mathrm{~m} * 200 \mathrm{~m})$} \\
\hline & 1970s & 1990s & $2010 \mathrm{~s}$ & 1970s & 1990s & $2010 \mathrm{~s}$ \\
\hline Type I.I & & & & & & \\
\hline
\end{tabular}

Table 6. Example of table for organising and comparing respective OUSs in the case of Mong Kok

\begin{tabular}{l|c|c|c}
\hline Year & 1975 & 1992 & 2014 \\
\hline Building density & 6.09 & 6.54 & 7.26 \\
\hline $\begin{array}{l}\text { Average distance to the nearest } \\
\text { neighbour distance }(m)\end{array}$ & 4.94 & 5.19 & 5.49 \\
\hline $\begin{array}{l}\text { Coverage of blocks } \\
\text { Average floor numbers }\end{array}$ & 0.67 & 0.63 & 0.66 \\
\hline Length of connected edges $(m)$ & 8.0 & 8.2 & 8.5 \\
\hline
\end{tabular}

Table 7. The parameters of OUSs in the case of Mong Kok

\section{Findings}

As building density in the study area of the Wan Chai District has been increasing at a much faster rate than in the study area of the Yau Tsim Mong District - from a similar starting point around the year 1975 - after three kinds of comparison, it was possible to reveal the the relationships between the evolution of OUSs with different increasing density rates. The similarities and differences between every type of OUS in the central area of the Wan Chai (around the Causeway Bay) and Yau Tsim Mong District (around the Mong Kok), can be categorised in a table and compared one by one. The relationship between the evolution of the pattern of OUS and increasing density can be summarised in four categories; $(\mathrm{I})$ both the increasing trend and increasing ratio of density influence the changes in the pattern of OUS. Type 1.3 and type 6.4 were classified in this category by considering the results below; (2) both the increasing trend and increasing ratio of density influence the changes in the pattern of OUS, but the 
different increasing ratio of density is not the most decisive factor for deciphering the changes. The representative cases of type I.I, type I.2, type 5.2, type 7.I and type 8.3 are all included in this category. Some other factors play a more important role in such changes when they change following increased density, such as their re-location, a change in land-use in their surroundings, and so on. (3) The increasing trend of density influences the changes in OUS, but the increasing ratio of density does not influence the changes. For example, the technologies available for construction and the aesthetics of commercial goods during the time in which building occurs can play more important roles in the process of change. Type 4 , type 2 , type 5.1 , type 6.1 , type 6.2 , type 6.3 , type 8.1 and type 8.2 are also considered to form part of this category; (4) neither the increasing trend nor the increasing ratio of density influence the changes to the pattern of OUS. The changes are only provoked by other factors. Type 3 and type 7.2 are distinguishable in this category.

After classifying the four categories or groups of different types of OUS, which have different relationships with increasing density, we particularly observed both maps and data in relation to representative cases, group by group. As the fourth group of spaces remains unchanged under the influences of increasing density and increasing ratio, we summarised the other three groups' main characteristics respectively. Although these characteristics appear more or less in all of the groups, one characteristic in particular shows up in a more obvious way in one group than in the others in our representative cases. (A) The first groups of OUS exhibit the main characteristic of transformation under social influences. These spaces perform the role of intervention and induction for the whole study areas rather than producing the optimised and integrated results observed in previous circumstances, including the environment of density and context of fabric. Regardless of whether or not the connections with surroundings are designed elaborately enough, these spaces have a responsibility to exude the temperament of contributing to previous compact and mixed-use residential areas to gain an irreplaceable and identifiable disposition in a city. (B) The second groups of OUS exhibit the main characteristic of transformation in cooperation with the driving forces that developed them. Although the increasing ratios of building density are different, the sizes and degrees of aggregation among identical types of OUS are very similar. However, spatial morphologies display relatively large differences. Neither the connecting edges with other spaces nor the overall shapes display any obvious similarity. (C) The third groups of OUS show the characteristics of a transformation mainly confined to spatial forms. Although the changes in spatial forms are not influenced by the increasing rate of density, driving forces as a result of commercialisation, privatisation, and introversion show advancements in OUSs. These driving forces push these processes to become independent and principal products of the OUS system rather than being parts of the spatial product in specific buildings. Therefore, it is speculated that changes to these spatial morphologies are decided neither by the increasing densities in relevant areas nor by the previous spatial forms themselves. The global backgrounds in specific periods, including economic and technological conditions, are the dominant factors, clues to which can be found in their forms. 


\section{Discussion}

Through the empirical studies of three periods in the study areas of the Wan Chai and Yau Tsim Mong Districts during 1975-2014, not only four kinds of relationships between increasing building density and patterns of OUS are drawn, but a further three trends of OUS transformation are presented. The new characteristics of contemporary OUS are also important references for future design in high-density cities. These trends of OUS can also explain the current conflicts related to recognition which have surrounded OUS in the last two decades.

(A) There is a stereotype that: social influences on contemporary OUSs in the study areas of the Wan Chai and Yau Tsim Mong Districts seem to drive their development towards homogeneity along with commercial drivers. Although most of the previous studies featuring this kind of stereotype are opposed to the influences arising from OUSs with commercial drivers, some rival ideas have appeared over the last decade. They are looking for alternative ways to develop these public spaces by re-evaluating the potential in and transformed meanings driven by commercial spaces for the public inhabiting these spaces. The gradual diversification of social influences within these spaces is not only related to the spaces in themselves but is also connected to the overall OUS system containing them. Additionally, as is the case for the immigration and emigration of major peoples in some OUSs, the solutions for the problems arising from such replacements of of diverse people can be sought as part of a larger-scale analysis rather than trying to digest and resolve the issue on middle or small scales independently.

(B) There is another stereotype in connection with the amount of reduction in OUSs along with observations that some spatial forms are not friendly enough for people to make contact with each other. Following the statistical analysis, it was concluded that the total area of most OUS with relatively high-openness, which have relatively more opposite attributions of OUS (Figure I), increased following an increase in density in the relevant area. At the same time, most OUSs tended to be transformed in a way that bestowed them with a relatively high level of public-ness; while, the boundaries of the OUSs tended to become softer and more irregular. The cognitive deviation for the reduction and increase of OUS is caused by the numerous new types of OUS, which took on the major roles of traditional OUSs. Although the projected area of many pre-existing OUSs for relatively high level of public use was not reduced or their types changed, their level of publicness lowered, because many of the newly built OUSs displayed much higher levels of public use and thus played stronger roles than their previous counterparts in terms of offering a high level of service to people.

(C) The third stereotype is that the impetus from the government and commerce are analysed respectively as two opposed forces in research works. However, the driving factors are becoming more diversified with more balanced forces from different aspects. The trends of impetus factors are closely related to the sustainable development of OUS. Otherwise, prioritising an increase in activities in a specific segment of OUS over other considerations leads to bias and inefficiency in terms of maintaining the vitality of OUS on a long-term basis: specifically in relation to the level of services offered the public. One of the main reasons for this 
is that visitors are gradually outnumbering local residents in OUS. The vitality of OUS should lie in ensuring a comfortable and efficient streaming of people rather than congestions and jams.

\section{References}

Abel, C. (200I). 'Architecture in the pacific century', Public places in asia pacific cities: current issues and strategies, MA: Kluwer Academic Publishers, Dordrecht, Boston, p. 4.

Al, S. (2016). Mall city: Hong Kong's dreamworlds of consumption, University Press, Hong Kong.

Anonymous (200I). 'The British Museum Queen Elizabeth II great court project fire engineering: enabling effective design for heritage buildings', Facilities, vol. 19, no. 10.

Aritenang, A.F. (20I4). 'Urbanization in Southeast Asia: issues and impacts', Bulletin of Indonesian Economic Studies, vol. 50, no. I, p.I44.

Backes, N. (1997). 'Reading the shopping mall city', Journal of Popular Culture, vol. 3I, no. 3, pp. I17.

Barter, P.A. (2000). 'Transport dilemmas in dense urban areas: examples from eastern asia', Compact cities: sustainable urban forms for developing countries, Spon Press, London.

Batty, M. (200I). 'Exploring isovist fields: space and shape in architectural and urban morphology', Environment and Planning B: Planning and Design, vol. 28, no. I, Pp. I23-I50.

Çalișkan, O. \& Marshall, S. (20I I). 'Urban morphology and design: introduction'. Built Environment, vol. 37, no. 4, pp. 380-392.

Carlow, J. (2013). '[Re]forming public space: a critique of hong kong's park governance through architectural intervention', Footprint, vol. I2, Pp. 67-74.

Carmona, M. \& Tiesdell, S. (2007), Urban design reader, Mass.: Architectural Press, Oxford. Burlington.

Chan, C.S. (2017). 'Health-related elements in green space branding in Hong Kong', Urban Forestry \& Urban Greening, vol. 21, pp. 192-202.

Chan, C.H. \& Fu, K.W. (2017). 'The relationship between cyber balkanization and opinion polarization: time-series analysis on Facebook pages and opinion polls during the Hong Kong occupy movement and the associated debate on political reform', Journal of Computer Mediated Communication, vol. 22, no. 5, pp. 266-283.

Chen, L, Ng, E., An, X., Ren, C., Lee, M., Wang, U., \& He, Z. (2012), 'Sky view factor analysis of street canyons and its implications for daytime intra-urban air temperature differentials in high-rise, high-density urban areas of Hong Kong: a GIS-based simulation approach', International Journal of Climatology, vol. 32, no. I, PP. I2I-I36.

Conzen, M.P.C. (200I), 'The study of urban form in the United States', Urban Morphology, vol. 5, no. I, PP. 3-I4.

Cugurullo, F. (2018), 'Exposing smart cities and eco-cities: Frankenstein urbanism and the sustainability challenges of the experimental city', Environment and Planning A: Economy and Space, vol. 50, no. I, pp. 73-92.

Darin, M. (2004), 'The study of urban form in Germany', Urban Morphology, vol. I, no. 8, pp. 9.

Edussuriya, P., Chan, A., \& Ye, A. (20II). 'Urban morphology and air quality in dense residential environments in Hong Kong. Part I: District-level analysis', Atmospheric Environment, vol. 45, no. 27, pp. 4789-4803.

District Council Election Constituency Boundaries (2015), Electoral Affairs Commission, Hong Kong. 
Eisenman, P. (20/2). 'The agency interview: the institute for architecture and urban studies (IAUS)', Perspecta, vol. 45, pp. 59-66.

Enke, S. (1962), 'Economic development with unlimited and limited supplies of labour', Oxford Economic Papers, vol. I4, no. 2, Pp. I58- 172.

Esber, G.S. (1982). 'Cultural/applied: human aspects of urban form: towards a man environment approach to urban form and design', American Anthropologist, vol. 84, no. 2, PP. 464-465.

Franck, K.A. \& Schneekloth, L.H. (1994). Ordering space: types in architecture and design, Van Nostrand Reinhold, New York.

Gao, W. (20I5). 'Collective actions for the management of multi-owned residential building: A case of Hong Kong', Habitat International, vol. 49, pp. 316-324.

Gray, J. (2013). 'The work of art in the age of mechanical reproduction', The Virginia Quarterly Review, vol. 89, no. 2, pp. 129-130.

Ghosh, S. (2015). 'Cities by design: the social life of urban form; explorations in urban design: an urban design research primer; the nature of urban design: a New York perspective on resilience', Journal of Urban Technology, vol. 22, no. 3, pp. 121-126.

Hart, K. (1973). 'Informal income opportunities and urban employment in Ghana'. Journal of Modern African Studies, vol. II, no. I, Pp. 61-89.

Haughton, G. (200I). 'Achieving sustainable urban form urban study', vol. 38, pp. I399-I 400.

Hillier, B. (2014). 'The generic city and its origins', Architectural Design, vol. 84, no. 5, pp. I00105.

Hofmeister, B. (2004). 'The study of urban form in Germany', Urban Morphology, vol. I, no. 8, Pp. 9.

Huang, J., Shen, G.Q. \& Zheng, H.W. (2015). 'Is insufficient land supply the root cause of housing shortage? Empirical evidence from Hong Kong', Habitat International, vol. 49, pp. 538-546.

Jayantha, W.M. \& Lam, S.O. (20I5). 'Capitalization of secondary school education into property values: a case study in Hong Kong', Habitat International, vol. 50, pp. 12-22.

Jayantha, W.M., Lam, T.I. \& Chong, M.L. (20I5). 'The impact of anticipated transport improvement on property prices: A case study in Hong Kong', Habitat International, vol. 49, Pp. I48-I56.

Jenks, M. \& Burgess, R. (2000). Compact cities: sustainable urban forms for developing countries, Spon Press, London

Jenks, M., Burton, E. \& Williams, K. (1996). The Compact city: a sustainable urban form? (Ist ed.), New York: E \& FN Spon, London.

Jia, B. (ed.) (2003). Dense living urban structure: selected papers of the International Conference on Open Building, 23-26 October, 2003, Hong Kong: Faculty of Architecture, The University of Hong Kong, Hong Kong.

Habraken, N.J. (2008). 'Design for flexibility', Building Research \& Information, vol. 36, no. 3, pp. 290-296. 
Helbrecht, I. \& Dirksmeier, P. (20I2). New urbanism: life, work, and space in the new downtown, Ashgate, Surrey, UK \& England.

Kai, G. (200I). 'Urban morphology of China in the post-socialist age: Towards a framework for analysis', Urban Design International, vol. 6, no. 3-4, pp. 125.

Kendall, S. (1999). 'Open Building: An Approach to Sustainable Architecture', Journal of Urban Technology, vol. 6, no. 3, pp. I-16.

Krasny, E. \& Wien, A.Z. (20I2). Hands-on urbanism I850-20I2: the right to green, MCCM Creation.

Lai, L.W.C. (20I5). 'Squatting by the privileged? A Hong Kong study on the innovations and ambiguity of property rights of irregular development', Habitat International, vol. 50, no. C, Pp. 317-325.

Li, W.M., Lee, S.C., \& Chan, L.Y. (200I). 'Indoor air quality at nine shopping malls in Hong Kong', Science of the Total Environment, vol. 273, no. I, pp. 27-40.

Maruani, T. \& Amit-Cohen, I. (2007). 'Open space planning models: A review of approaches and methods', Landscape and Urban Planning, vol. 8I, no. I, Pp. I-I3.

Marzot, N. (2002). 'The study of urban form in Italy', Urban Morphology, vol. 6, no. 2, pp. 59-73.

Mesa, N.A., Corica, L., \& Pattini, A. (20I I), 'Evaluation of the potential of natural light to illuminate buildings in dense urban environment, a study in Mendoza, Argentina', Renewable Energy, vol. 36, no. 9, pp. 24I4-2423.

Miao, P. (ed.) (200I). Public places in Asia Pacific cities: current issues and strategies, MA: Kluwer Academic Publishers, Dordrecht, Boston.

Miles, M., Hall, T., \& Borden, I. (ed.) (2004). The City cultures reader (2nd ed.), Routledge, London \& New York.

Mindali, O., Raveh, A., \& Salomon, I. (2004). 'Urban density and energy consumption: a new look at old statistics', Transportation Research Part A, vol. 38, no. 2, pp. I43-I62.

Moneo, R. (1978). 'On Typology', Oppositions, Institute for Architecture Urban Studies, New York.

Mostafavi, M. \& Najle, C. (2000). 'Urbanism as landscape?' AA Files, vol. 42, no. I, pp. 44-47.

Moudon, AV 1992, 'A catholic approach to organizing what urban designers should know', Journal of planning literature, vol. 6, no. 4, Pp. 33I-349.

Munton, R. \& Collins, K. (1998). 'Government strategies for sustainable development', Geography, vol. 83, pp. 346-357.

Nagendra, H. \& Gopal, D. (2010). 'Street trees in Bangalore: Density, diversity, composition and distribution', Urban Forestry \& Urban Greening, vol. 9, no. 2, Pp. I29-I 37.

Norberg-Schulz, C. (1976). 'The Phenomenon of Place', Architectural Association Quarterly, vol. 8, no. 4, pp. 3-10.

Shi, W., Jia, B. \& Wee, H.K. (20I6). 'Evolution of space pattern in the increasing high-dense city', Urban Morphology and the Resilient City, vol. I, no. I, pp. 128-I43.

Shi, W., Jia, B. \& Wee, H.K. (20I7). 'Multi-Level: a way to study the pattern of urban open space in high-density environment', UIA 2017 Seoul World Architects Congress, vol. I, no. I. 
Shi, W., Jia, B. \& Wee, H.K. (2018). 'Relationship between the changing urban open spaces and increasing density in Mong Kok since the 1970s', Modern Environmental Science and Engineering, vol. 4, no. 5, pp. 476-486.

Storper, M., \& Scott, A.J. (2016). 'Current debates in urban theory: a critical assessment', Urban Studies, vol. 53, no. 6, Pp. III4-II36.

Thompson, I. (2000). 'The city cultures reader. Landscape research', vol. 25, no. 2, pp. 259.

Tucker, D 2002, 'Public places in Asia pacific cities: current issues and strategies great leap forward', The Journal of Asian Study, vol. 6I, pp. I0I2-I0I4.

Wai, M.K., Yee, C.W., Tim, W.L. \& Shan, H.P. (2010). 'Scoping indoor airborne fungi in an excellent indoor air quality office building in Hong Kong', Building Services Engineering Research \& Technology, vol. 3I, no. 2, pp. 19I-199.

Wan, C. \& Shen, G.Q. (20I5). 'Salient attributes of urban green spaces in high density cities: the case of Hong Kong', Habitat International, vol. 49, pp. 92-99.

Wang, H., Zhang, X., \& Skitmore, M. (20I5). 'Implications for sustainable land use in high-density cities: evidence from Hong Kong'. Habitat International, vol. 50, pp. 23-34.

Wang, Y., \& Chen, J. (2018). 'Does the rise of pseudo-public spaces lead to the "end of public space" in large Chinese cities? Evidence from Shanghai and Chongqing', Urban Design International, vol. 23, no. 3, pp. 215-235.

Willams, N. (200I). 'Achieving sustainable urban form: $K$ Williams, E Burton and M Jenks E \& FN Spon, London, 388pp', Land Use Policy, vol. I8, pp. 202-202.

Woels, M. (2012). 'Hands-on urbanism, I850-2012: the right to green archit. Rev', svol. 23I, pp. 97.

Wu, C., Wilkes, R., Silver, D., \& Clark, T.N. (2019), 'Current debates in urban theory from a scale perspective: Introducing a scenes approach', Urban Studies, vol. 56, no. 8, Pp. I4871497.

Xue, C.Q.L. \& Manuel, K.K. (200I). 'The quest for better public space: a critical review of urban Hong Kong', Public places in Asia Pacific cities: current issues and strategies, MA: Kluwer Academic Publishers, Dordrecht, Boston.

Xue, C.Q.L. (20I2). 'Indoor public space: a study of atria in mass transit railway (MTR) complexes of Hong Kong'. Urban Design International, vol. I7, no. 2, pp. 87-I05.

Yau, Y. \& Chiu, S.M. (2015). 'Combating building illegality in Hong Kong: a policy delphi study', Habitat International, vol. 49, pp. 349-356. 